\title{
The practice and effectiveness of ecological operation experiment on spawning of the four major Chinese carps by Three Gorges Reservoir
}

\author{
Wei Xu, Xiaojuan Chen, Jiangping Tao, Cao Jun \\ ${ }^{1,2}$ Key Laboratory of Ecological Impacts of Hydraulic Projects and Restoration of Aquatic Ecosystem of the Ministry of Water Resources, \\ Institute of Hydroecology, Ministry of Water Resources \& Chinese Academy of Sciences,
}

\begin{abstract}
Eco-operation experiment by the Three Gorges Reservoir was carried out ten times to facilitate spawning of the four major Chinese carps in the lower reaches of Yangtze River, from 2011 to 2017. To get knowledge of fish spawning response to man-made flood process, and also assessing the positive effect of eco-operation on fish spawning, fish eggs were monitored daily by drift-net method, in a fixed profile in Shashi reach between mid-May to mid-July each year. Basing on the consecutive data and research for seven years, the practice and effectiveness of TGR eco-operation experiment on fish spawning were summarized and prospected. The main findings were as follows: eco-operation experiment usually operated in a suitable condition from late May to the end of June. Based on the hydrological monitoring data in Yichang station, the continuous days of rising limb varied from 3 days to 9 days, the mean diurnal increment of water level varied from $0.43 \mathrm{~m}$ to $1.30 \mathrm{~m}$, and the water temperature varied from $20^{\circ} \mathrm{C}$ to $24^{\circ} \mathrm{C}$, except in 2013 that only below $18^{\circ} \mathrm{C}$, during eco-operation period within seven years. According to the fish eggs monitoring data in Shashi reach, annual egg abundance of the four major Chinese carps ranged from 116 to 610 million, grass carps and silver carps were two dominant species with proportion of more than $80 \%$. Egg abundance of the four carps produced in eco-operation period accounted for about $38 \%$ averagely of total amount in the whole monitoring period, with nine floods in total of thirty-three floods. Four indicators representing fish spawning performance, the time interval from water rising to spawn happening, duration time of spawning, extent of spawning grounds, and spawning scale, were calculated in each spawning event corresponding to each flood process. All indicators gave evidence that spawning performance of the four carps were better in eco-operation period, compared with other routine operation period. It was concluded the Three Gorges Reservoir eco-operation had done its work on boosting spawning of the four major Chinese carps, but further and foremost research should be developed on the following aspects, quantifying the eco-operation effect, optimizing the eco-operation index, and extending the eco-operation target to other important life history stage of fishes.
\end{abstract}

\section{Introduction}

The four major Chinese carps were common name of four endemic fishes consist of grass carp, silver carp, bighead carp and black carp, as they played very important role in both cultivation and capture freshwater fishery in China [1, 2]. Yangtze River was a natural origin of the four carps, and their major habitats largely located in the middle reach, with spawning scale from Yichang to Chenglingji reach contributed to $42.7 \%$ of Yangtze mainstream historically [3, 4]. The requirements of FMCC spawning were specific and rigorous, such as typically spawned in large and turbid rivers; the lowest water temperature for spawning was $18^{\circ} \mathrm{C}$, spawning peak occurred at 21 to $24^{\circ} \mathrm{C}$, increase of river flow was the key triggering factors, eggs and larvae must drift in the current until they matured enough to migrate into nursery habitats[5 7]. The resource dynamics of the four carps could represent the health state of river ecosystem because of their long term adaption to river-lake integral ecosystems in the middle and lower reaches of Yangtze River. These characteristics made them receive much attention during the construction and operation of Three Gorges Project [8].

The Three Gorges Project in China is one of the biggest hydro-power engineering projects worldwide. According to TGP operation rules, The Three Gorges Reservoir (TGR) would balance water discharge both in May and June, which caused flood process in downstream more smoothly and discharged water temperature lower than the natural condition. Therefore, two important factors for the spawning of four carps, river flow increase and water temperature changed inevitably [9, 10]. Many research verified that the degradation of the four carps spawning had a close

\footnotetext{
*Corresponding author: Wuhan, China, betty3115@126.com
} 
association with the changes in hydrological and thermal conditions caused by the TGR [11 13].

In order to enhance the natural reproduction of the four carps, the TGR operation could adjust in several days to create a suitable flood process favored fish spawning, which was called 'eco-operation'. Experiment of eco-operation was put into practice first time in June 2011. From then on, the eco-operation kept carrying on for one or two times every year. Although preliminary result showed the spawning of four carps and other fishes had good response to the eco-operation flood[14, 15], something must be done to sum up the experience of TGR eco-operation, such as characteristic of flood process, regular pattern of fish spawning, and further effect of eco-operation. Basing on the monitoring data in Shashi section from 2011 to 2017, this paper focused on three aspects, the implementation of TGR eco-operation, the spawning trait of the four major Chinese carps, and the effect of TGR eco-operation on fish spawning.

\section{Implementation of eco-operation from 2011 to 2017}

TGR

From 2011 to 2017, a total of ten times of TGR

\begin{tabular}{|c|c|c|c|c|c|c|}
\hline \multirow{2}{*}{ year } & $\begin{array}{c}\text { the date during } \\
\text { period of TR } \\
\text { eco-operation }\end{array}$ & $\begin{array}{c}\text { the starting } \\
\text { discharge } \\
\text { flow of TGR }\end{array}$ & $\begin{array}{c}\text { mean diurnal } \\
\text { increment of } \\
\text { discharge } \\
\text { flow }\end{array}$ & $\begin{array}{c}\text { continuous } \\
\text { days of flow } \\
\text { increase }\end{array}$ & $\begin{array}{c}\text { mean diurnal } \\
\text { increment of } \\
\text { water level in } \\
\text { Yichang }\end{array}$ & $\begin{array}{c}\text { mean water } \\
\text { temperature in } \\
\text { Yidu section }\end{array}$ \\
\hline 2011 & $6.16-6.19$ & 12000 & 1650 & 4 & 0.88 & 23.6 \\
\hline \multirow{2}{*}{2012} & $5.25-5.31$ & 18300 & 2600 & 4 & 1.02 & 20.5 \\
\hline \multirow{2}{*}{2013} & $6.20-6.27$ & 12600 & 1550 & 4 & 0.64 & 22.3 \\
\hline 2014 & $5.7-5.14$ & 6230 & 1100 & 9 & 0.51 & 17.5 \\
\hline \multirow{2}{*}{2015} & $6.4-6.6$ & 14600 & 1450 & 3 & 0.46 & 20.3 \\
\hline \multirow{2}{*}{2016} & $6.7-6.10$ & 6530 & 3130 & 4 & 1.3 & 21.6 \\
\hline \multirow{2}{*}{2017} & $6.25-7.2$ & 14800 & 1930 & 3 & 0.86 & 22.5 \\
\cline { 2 - 7 } & $6.9-6.11$ & 14600 & 2100 & 3 & 0.55 & 21.8 \\
\hline
\end{tabular}

spawning usually was in late June and early July. The spawning period by the monitoring lasted about two

\section{Spawning trait of the four major Chinese carps}

\subsection{Spawning time and frequency}

By the initial and final date that sampled eggs of the four carps, The starting time of the carps spawning usually at latter half of May, the earliest was in May 13, 2013 and the latest was in June 5, 2014. The ending time of eco-operation were carried out in seven years, with one or two times each year. The eco-operation only implemented during late May to the end of June to coordinate spawning time and TGR regulation. In the original eco-operation plan, operation indexes including the starting of TGR discharge flow, diurnal increment of discharge flow, continuous days of flow increase, and terminal discharge flow, were explicit to make TGR operable. Due to discrepancy of hydrological regime in time and space among years, and considering other water needs, the implementation of TGR eco-operation were different in timing and extent. The basic information and operation indexes during each eco-operation from 2011 to 2017 were concluded in table 1 . The starting discharge flow by TGR varied from 6230 to $18300 \mathrm{~m}^{3} \mathrm{~s}^{-1}$, and mean diurnal increment of TGR discharge flow varied from 1100 to $3130 \mathrm{~m}^{3} \mathrm{~s}^{-1}$. Yichang hydrological station was the first monitoring section located in the downstream of TGR, monitoring data showed the continued days of rising limb varied from 3 days to 9 days, the average diurnal increment of water level varied from $0.43 \mathrm{~m}$ to $1.30 \mathrm{~m}$, and the water temperature varied from $20^{\circ} \mathrm{C}$ to $24^{\circ} \mathrm{C}$, except in $2013\left(17.5^{\circ} \mathrm{C}\right)$, in Yichang reach.

\section{months, which was a little shorter than the historical} record (May to July). In figure 1, the frequency of spawning peak was about three and four times each year, mainly occurred in three period of time, the end of May, the late June and the early July. The frequency of scattered spawning was about two and three times each year, mainly occurred in the first and middle third of June. 


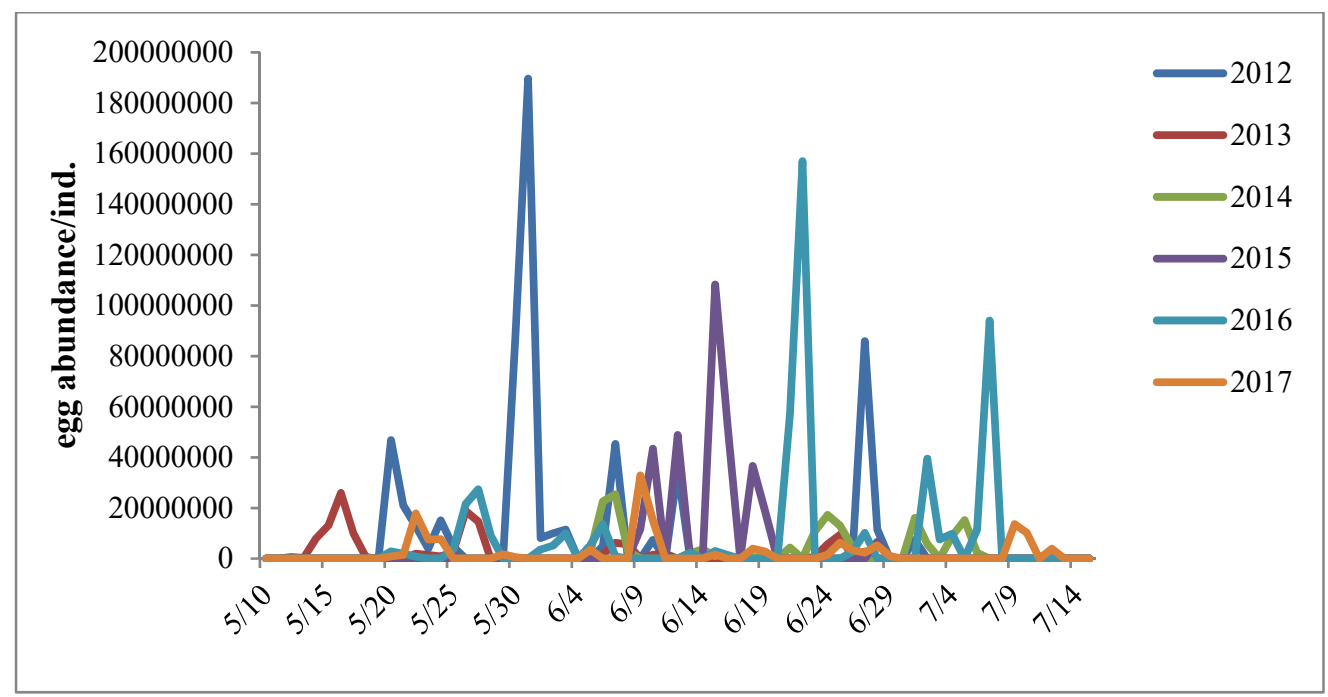

Fig. 1 the daily variation of egg abundance from 2011 to 2017

\subsection{Annual abundance and composition}

The annual egg abundance of four carps was 610 million, 116 million, 161 million, 326 million, 502 million and 145 million, from 2012 to 2017, indicating the population of four carps fluctuated obviously year by year. The data in 2011 was omitted, since the monitoring period only covered one month. Figure 2 showed the species composition had some variation among years, but generally grass carps and silver carps were two dominant species with proportion of more than $80 \%$. Black carps and bighead carps maintained a lower abundance, especially for bighead carps.

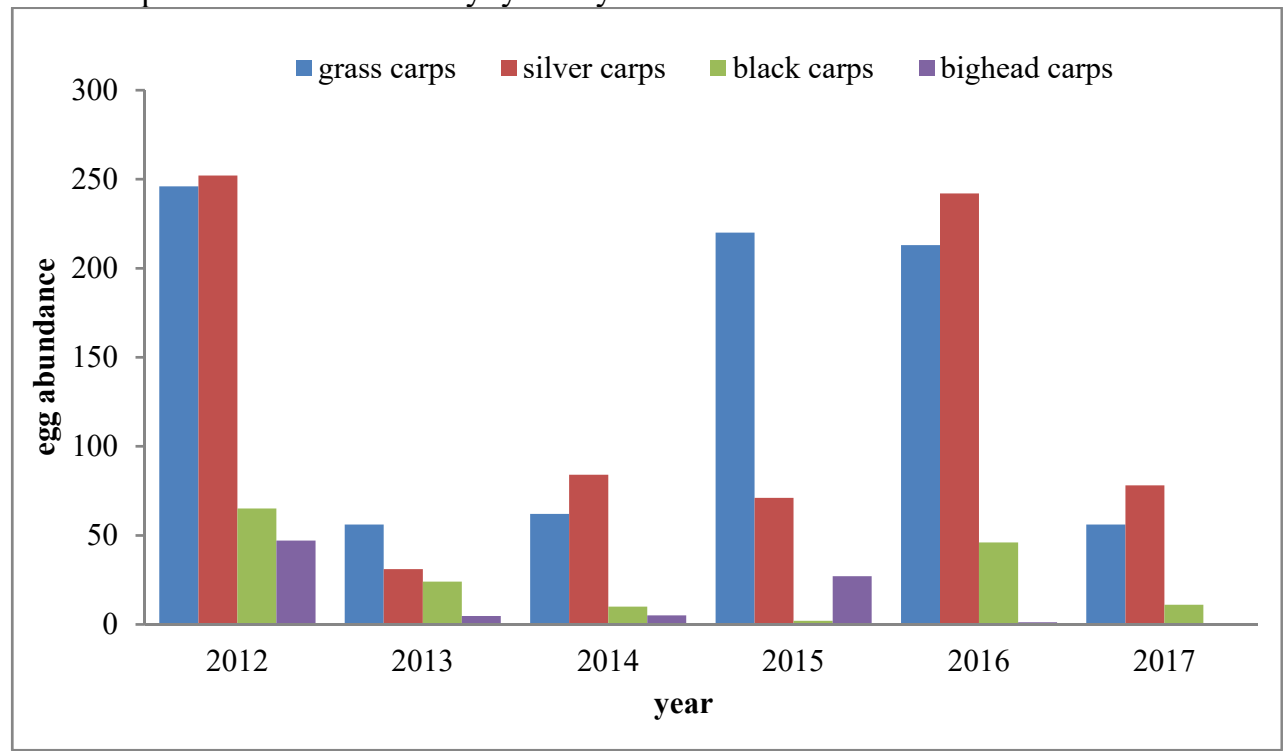

Fig. 2 composition of four carps in egg abundance from 2012 to 2017

spawning scale was biggest for Dongshi with average of $20.94 \%$, next was for Zhicheng with average of $18.98 \%$.

\subsection{Spawning location and scale}

As for the spawning locations, Jiangkou, Dongshi, Songzi and Zhicheng were four stable spawning grounds below Yichang city. The length of spawning ground was longest in Zhicheng with average of $14.5 \mathrm{~km}$, next was in Dongshi with average of $7 \mathrm{~km}$. The proportion of
Songzi showed notable spawning scale only in 2015, while Jiangkou showed none spawning in the same time. There were other two spawning grounds located in Yuanshi and Shashi showed scattered spawning in few years. With tiny spawning scale, the statistical data was omitted in table 2.

Table.2 spawning scale and length in different spawning grounds from 2012 to 2017

\begin{tabular}{ccccccccc}
\hline \multirow{2}{*}{ Item } & \multirow{2}{*}{ Spawning ground } & \multicolumn{7}{c}{ Year } \\
\cline { 3 - 8 } & & 2012 & 2013 & 2014 & 2015 & 2016 & 2017 & Average \\
\hline \multirow{2}{*}{$\begin{array}{c}\text { Spawning } \\
\text { scale }\end{array}$} & Jiangkou & 1.8 & 12.02 & 18.25 & 0 & 21.36 & 18.08 & 11.92 \\
& Dongshi & 5.99 & 17.93 & 18.25 & 26.15 & 23.53 & 33.79 & 20.94
\end{tabular}




\begin{tabular}{|c|c|c|c|c|c|c|c|c|}
\hline \multirow[t]{2}{*}{$(\%)$} & Songzi & 3.59 & 0 & 9.52 & 33.85 & 3.73 & 0.91 & 8.60 \\
\hline & Zhicheng & 13.77 & 35.42 & 16.67 & 17.23 & 8.98 & 21.8 & 18.98 \\
\hline \multirow{4}{*}{$\begin{array}{c}\text { Spawning } \\
\text { length } \\
(\mathrm{km})\end{array}$} & Jiangkou & 7 & 4 & 3 & 0 & 10 & 8 & 5.33 \\
\hline & Dongshi & 5 & 12 & 10 & 5 & 4 & 6 & 7.00 \\
\hline & Songzi & 4 & 0 & 5 & 4 & 2 & 1 & 2.67 \\
\hline & Zhicheng & 20 & 25 & 15 & 8 & 1 & 18 & 14.50 \\
\hline
\end{tabular}

abundance of one spawning event varied from 1.22 (in June 14, 2017) to 308.4 (in May 29 to June 1, 2017)

\section{Effect of TGR eco-operation on fish spawning}

\subsection{Spawning response to hydrograph}

Most times of four carps spawning happened in the rising limb of hydrograph and very few happened in the recession limb of hydrograph, while carps would never spawn in the condition of water subsiding (Figure 3, 4). It was again proved the river flow increase was indispensable to the four carps spawning. Figure 3 and 4 also showed the daily egg abundance of four carps had concurrent variation along with flood process, respectively in 2012 and 2017 . The duration time of one spawning event ranged from 1 to 6 days and the total egg million, mainly depended on the population participating in breeding, as well as the duration time of freshet.

To know how the four carps spawning to response eco-operation flood, Figure 5 showed egg abundance of the four carps produced in eco-operation period accounted for about $38 \%$ averagely (ranged from $0.48 \%$ to $66.56 \%$ ) of total amount in the whole monitoring period, with flood frequency 9 times in the former and 33 times in the latter. An exception was in 2016, the four carps could hardly spawn in the eco-operation period. The reasons might be that it was high flow year in 2016, the hydrological condition for fish spawning was good enough, and before eco-operation carried out, the four carps had just spawned for about three and four times.

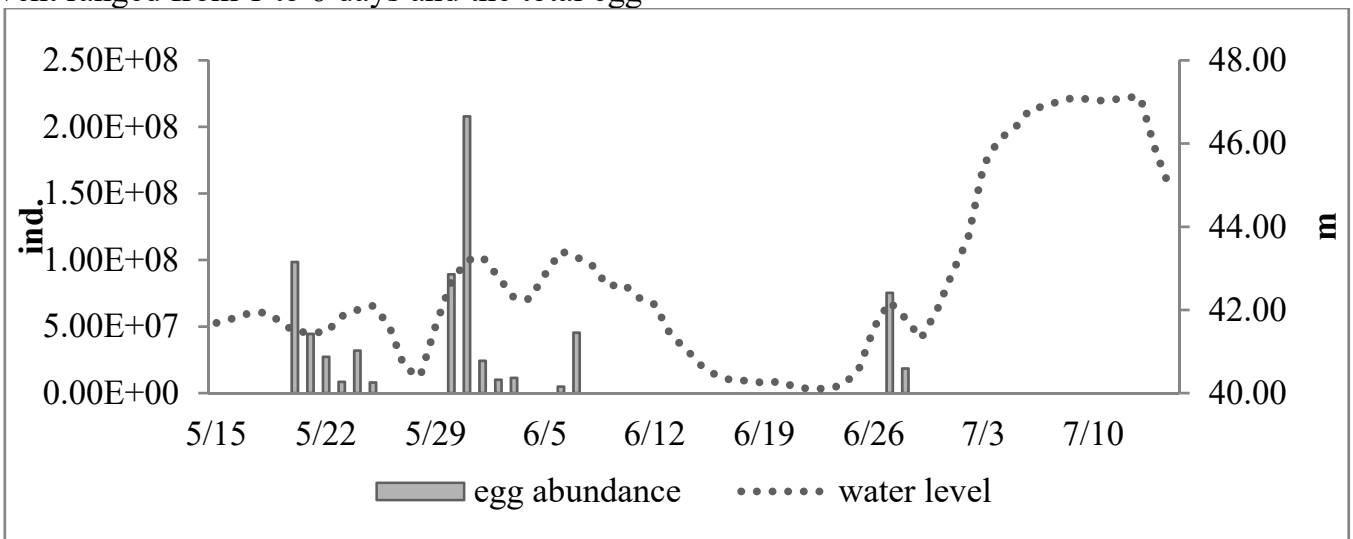

Fig. 3 relations of daily egg abundance of four carps and water level in 2012

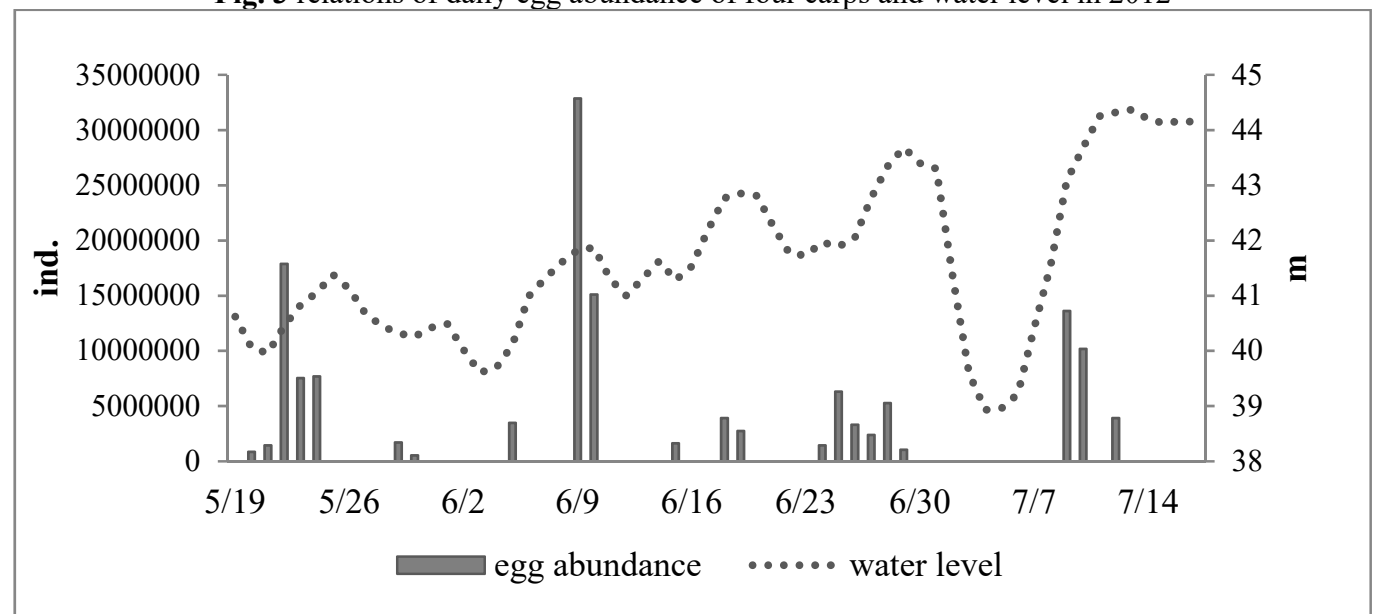

Fig. 4 relations of daily egg abundance of four carps and water level in 2017 


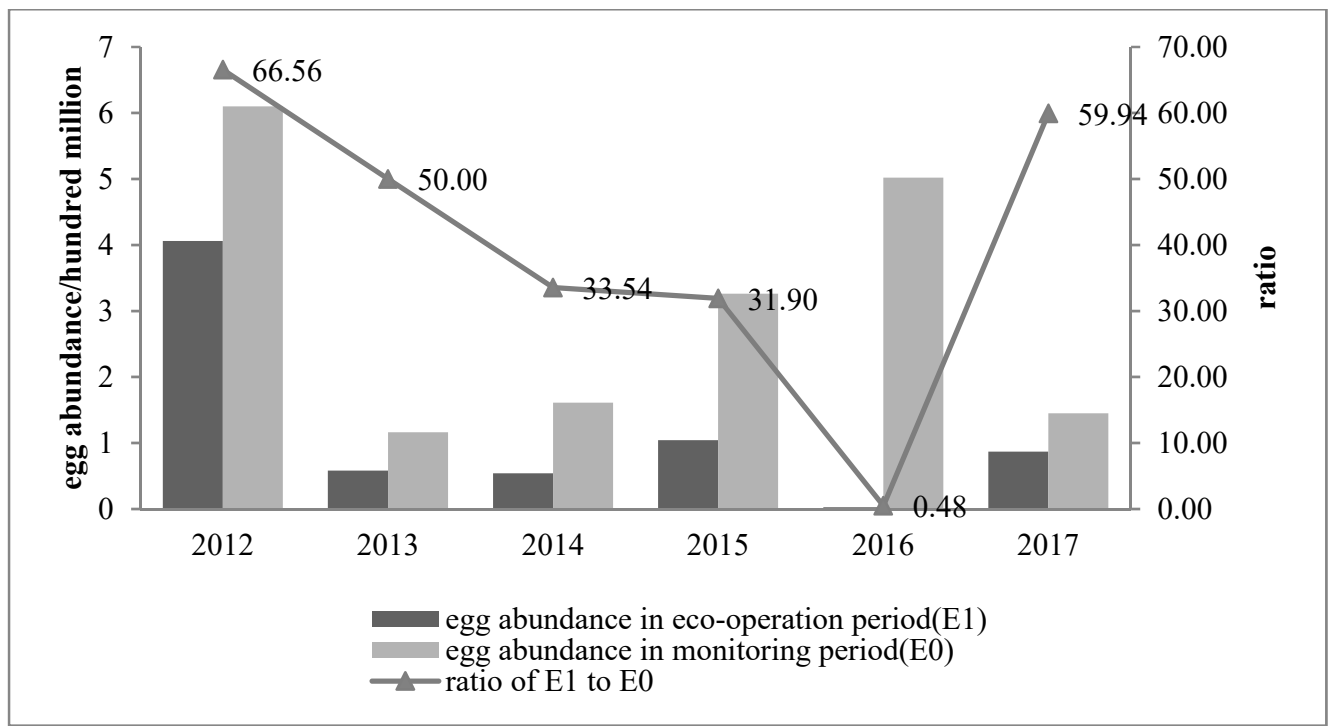

Fig. 5 egg abundance in eco-operation period and monitoring period

\subsection{Comparison of spawning performance between eco-operation and routine-operation}

It had proved that a suitable flood condition could produce a successful spawning event. To assess the effectiveness of TGR eco-operation, four indicators were selected to give evidence of the discrepancy in spawning performance with different flood operation mode. They were the time interval from water rising to spawn happening (SP1), duration time of spawning (SP2), extent of spawning grounds (SP3), and the spawning scale (SP4). For each spawning event with scale larger than 10 million, these indicators were calculated in each year. There were 22 data groups of calculated indicators, representing 22 times of spawning event, in which 7 times was in eco-operation mode. The variation range of each indicator was from -2 to 6 days in SP1, from 2 to 6 days in SP2, from 17 to $106 \mathrm{~km}$ in SP3, from 2 to 4 species in SP4, and from 13.39 to 308.4 million individuals in SP5.

Comparison of mean value for each indicator Table.3 mean and range value of indicators of spawning performance

\begin{tabular}{|l|c|c|c|c|}
\hline \multicolumn{1}{|c|}{ Flood mode } & item & $\begin{array}{c}\text { SP2 } \\
(\text { days })\end{array}$ & $\begin{array}{c}\text { SP3 } \\
(\mathrm{km})\end{array}$ & $\begin{array}{c}\text { SP4 } \\
\text { (million) }\end{array}$ \\
\hline eco-operation & mean & 4 & 83 & 92.54 \\
& range & $3 \sim 5$ & $56 \sim 106$ & $35.41 \sim 308.4$ \\
\hline \multirow{2}{*}{ routine-operation } & mean & 3 & 68 & 61.64 \\
& range & $2 \sim 6$ & $17 \sim 105$ & $13.39 \sim 214.38$ \\
\hline
\end{tabular}

TGR had done its work on boosting spawning of the four major Chinese carps, just because spawning performance during eco-operation flood mode was preferable to that during routine-operation flood mode. The practice of TGR eco-operation was first attempt aiming to help spawning of important fishes. Experience in proposal, implementation, monitoring and assessment of TGR eco-operation had achieved during these years, which could be good example for other similar hydro-power project. However, further and foremost research should be developed on the following aspects, quantifying the eco-operation effect, optimizing the eco-operation index, and extending the eco-operation target to other important life history stage of fishes. 


\section{Acknowledgement}

We gratefully acknowledge all colleagues for their long-term field surveys. This study was supported by China Three Gorges Corporation, the National Natural Science Foundation of China (Grant 51609156), and the National key Research and Development program of China (Grant 2016YFC0402204).

\section{References}

1. Collaboration Group of Yangtze River fishery resources survey. Fishery resources in the Yangtze River system. Maritime Press, Beijing, China. 1990

2. Li Si-fa. A study on biodiversity and its conservation of major fishes in the Yangtze River [M]. Shanghai: Shanghai Scientific \& Technical Publishers, 2001

3. Yi B., Yu Z., Liang Z., Sujuan S., Xu Y., Chen J. et al. The distribution, natural conditions, and breeding production of the spawning ground of four famous freshwater fishes on the main stream of the Yangtze River. In: Gezhouba Water Control Project and Four Famous Fishes in the Yangtze River (Eds B. Yi, Z. Yu \& Z. Liang), pp. 1-46. Hubei Science and Technology Press, Wuhan, China, 1988

4. Yu Z T., Deng Z L., et al. Current situation and impact assessment on the spawning ground of Four Chinese carps on the main stream of the Yangtze River after construction of Gezhouba Water Control Project. In: Gezhouba Water Control Project and Four Famous Fishes in the Yangtze River (Eds B. Yi, Z. Yu \& Z. Liang), pp. 1-46. Hubei Science and Technology Press, Wuhan, China. 1988, 47-68

5. Zhang G, Chang J, Shu G. Application of factor-criteria system reconstruction analysis in the reproduction research on grass carp, black carp silver carp and bighead in the Yangtze River. Int $J$ Gen Syst 2000, 29:419-428

6. Kolar CS, Chapman DC, Courtenay WR, Housel CH, Williams JD, Jennings DP. Bigheaded carps: a biological synopsis and environmental risk assessment. American Fisheries Society Special Publication, 2007, 33

7. Chen Y B., Liao W G., Peng Q D., et al. A summary of hydrology and hydrodynamics conditions of Four Chinese Carps' spawning. Journal of Hydroecology, 2009, 2(2): 130-133

8. Wei Xu, Qihong Yang, Huiyuan Tang, Honggao Liu. Natural Reproduction of the Four Major Chinese Carps in mainstream of Yangtze River (from Yichang to Shashi) Responding to Ecological Operation of Three Gorges Reservoir. The 3rd Biennial Symposium of the International Society for River Science, Conferrence Proceedings, 2013: 704-711

9. Deng Yun, Xiao Yao, Tuo Youcai and He Taifu. Influence of Three Gorges reservoir on water temperature between Yichang and Jianli. Advances in Water Science. 2016, 27(4): 551-560
10. Guo Wenxian, Wang Hongxiang, Xu Jianxin, Xia Ziqiang. Effects of Three Gorges reservoir on the downstream eco-hydrological regimes during the spawning of important fishes. Journal of Hydroelectric Engineering, 2011, 30(3): 22-26(38)

11. Duan, X. B.; Liu, S. P.; Huang, M. G; Qiu, S. L.; Li, Z. H.; Wang, K; Chen, D. Q., 2009: Changes in abundance of larvae of the four domestic Chinese carps in the middle reach of the Yangtze River, China, before and after closing of the Three Gorges Dam. Envir. Biol. of Fish. 86: 13-22.

12. Cai Yupeng, Yang Zhi, Xu Wei. Effect of water temperature variation after impoundment of the Three Gorges reservoir on natural reproduction of the four major Chinese carps. Advanced Engineering Sciences, 2017, 49(1): 70-77

13. Peng Qidong, Liao Wengen, Li Chong, $\mathrm{Yu}$ Xuezhong. Impacts of four major Chinese carps' natural reproduction in the middle reaches of Changjiang River by Three Gorges project since the impoundment. Journal of Sichuan University (engineering science edition), 2012, 44, Supp.2: 228-232

14. W. Xu, Y. Qiao, X.-J. Chen, Y.-P. Cai, Z. Yang and H.-G. Liu. 2015. Spawning activity of the four major Chinese carps, in middle mainstream of the Yangtze River, responding to the three Gorges Reservoir operation. Journal of Applied Ichthyology, 31(5): 846-854

15. Xu W., Liu H.G., Tang H.Y., Zhu D., Yang Z., Qiao Y. (2014). Effects of ecological operation of Three Gorges Reservoir on fish eggs and larvae in Shashi section of the Yangtze River. $J$ Hydroecology, 35, $1-8$ 